\title{
Authenticity Anyone? The Enhancement of Emotions via Neuro-Psychopharmacology
}

\author{
Felicitas Kraemer
}

Received: 24 October 2009/Accepted: 27 April 2010/Published online: 15 May 2010

(C) The Author(s) 2010. This article is published with open access at Springerlink.com

\begin{abstract}
This article will examine how the notion of emotional authenticity is intertwined with the notions of naturalness and artificiality in the context of the recent debates about 'neuro-enhancement' and 'neuro-psychopharmacology.' In the philosophy of mind, the concept of authenticity plays a key role in the discussion of the emotions. There is a widely held intuition that an artificial means will always lead to an inauthentic result. This article, however, proposes that artificial substances do not necessarily result in inauthentic emotions. The literature provided by the philosophy of mind on this subject usually resorts to thought experiments. On the other hand, the recent literature in applied ethics on 'enhancement' provides good reasons to include real world examples. Such case studies reveal that some psychotropic drugs such as antidepressants actually cause people to undergo experiences of authenticity, making them feel 'like themselves' for the first time in their lives. Beginning with these accounts, this article suggests three nonnaturalist standards for emotions: the authenticity standard, the rationality standard, and the coherence standard. It argues that the authenticity standard is not always the only valid one, but that the other two ways
\end{abstract}

F. Kraemer $(\bowtie)$

Section of Philosophy \& Ethics,

Eindhoven University of Technology,

IPO 1.01, PO Box 513, 5600 MB Eindhoven,

The Netherlands

e-mail: f.kraemer@tue.nl of assessing emotions are also valid, and that they can even have repercussions on the felt authenticity of emotions. In conclusion, it sketches some of the normative implications if not ethical intricacies that accompany the enhancement of emotions.

Keywords Neuro-enhancement - Authenticity · Emotions $\cdot$ Prozac $\cdot$ Naturalness $\cdot$ Artificiality

\section{Introduction: The Enhancement of Emotions and its Role in Emotional Authenticity}

According to Charles Taylor, American society is committed to an ideal of authenticity, or even to an 'ethics of authenticity,' that has its roots in Puritanism. ${ }^{1}$ This ethics of authenticity demands that each person should strive for self-perfection, should make the best out of life, and should actualize hidden potential. In a capitalist or neo-liberalist society, those who fail to meet this standard of ongoing selfactualization and self-optimization are regarded as losers who lead unhappy and unfulfilled lives [2-4].

Perceived in this manner, 'authenticity' has become a key notion in recent literature on 'enhancement' in applied ethics; people long for personal authenticity and therefore use enhancement techniques [40]. According to Eric Juengst [5]: $29 \mathrm{f}$., the

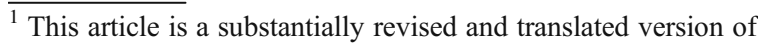
the essay: [1].
} 
term 'enhancement' is used to 'characterize interventions designed to improve human form or functioning beyond what is necessary to sustain or restore good health.' Enhancement usually does not 'respond to medical needs,' but aims to make a healthy person feel better. It is thus opposed to treatment or therapy. In order to find their 'true selves,' people wish to improve their outer appearance via cosmetic surgery and their physical and cognitive performance via doping and smart drugs. Most importantly, they also enhance their subjective emotional well-being through lifestyle drugs $[2,6]$. In this vein, the enhancement of affective states is a way of changing a person's 'natural' emotional life by intervening with artificial means. Emotions are mostly enhanced pharmacologically, that is, through psychotropic lifestyle drugs designed in line with recent insights of brain research (see, e.g., [2, 6-8]). In addition, there are new treatments for the sick that influence emotions through 'deep brain stimulation' (DBS) via brain pacemakers for Parkinson's patients, and transcranial magnetic stimulation (TMS), which is used to treat depression. It is unclear whether healthy people will ever use these technologies as enhancement devices in the future. Already nowadays, however, even healthy people who do not suffer from depression in the medical sense use psychopharmacological drugs to feel better and to enhance their social performance.

Among the neuro-enhancement strategies already on the market, this paper will therefore focus on psychopharmacological enhancement, and especially on the antidepressant Fluoxetine, which is a selective serotonin reuptake inhibitor commonly known as Prozac. Prozac is an especially widespread drug, and there has already been considerable research done on the philosophical questions and social effects, including work by psychiatrist Peter Kramer [9] and ethicist Carl Elliott [2]. The specific contribution to the debate that this paper attempts to provide consists in the answer to the following research question: 'Can emotional authenticity or inauthenticity be inferred from the naturalness or artificiality of the devices employed, here from the intake of Prozac as an enhancement drug?' In other words: Does the consumption of Prozac and similar new psychopharmacological drugs necessarily lead to inauthentic emotions, or could it even lead to emotional authenticity?
As Peter Kramer points out, Prozac is not simply a mood-brightener. Rather, it is a highly efficient drug that transforms a person's character and emotional disposition as a whole ([9]: $10 \mathrm{f}$.). According to Kramer's and Elliott's research, Prozac can even be regarded as an authenticity-generating drug. This assumption requires further investigation. The main effect of Prozac is to relieve a person from social anxieties. While using Prozac, some shy people may become talkative and easygoing. After only some weeks on the medication, some individuals with a traumatic history find a way of dealing with the past and creating a positive attitude toward the future. They become active and selfconfident. A paradigmatic case is Peter Kramer's patient Tess ([9]: 1-21; 278).

Tess was 'the eldest of ten children born to a passive mother and an alcoholic father in the poorest housingproject in our city,' as Kramer writes. She had suffered 'neglect and abuse' during her childhood ([9]: 1;3). When she was twelve, her father died and her mother fell into a permanent clinical depression. At that point, Tess 'took over the family' and managed to 'steer all nine siblings into stable jobs and marriages,' and even made a 'business career' herself ([9]: $1 \mathrm{f}$.).

Despite her success in all these respects, when Tess appears at Kramer's practice, she leads an unhappy personal life. She stumbles from one abusive partnership into the next ([9]: 2) and becomes more and more depressed. At some point, she shows all the symptoms of depression: 'Tears and sadness, absence of hope, inability to experience pleasure, sense of worthlessness, loss of sleep and appetite, guilty ruminations, poor memory and concentration' ([9]: 3). Kramer is especially specific about her 'low self-worth' and her 'social unhappiness' when it comes to personal relations ([9]: 4).

The first step Kramer takes is to put her on imipramine, an old antidepressant that made her feel drowsy. Despite these side-effects, the medication works well and saves her from falling into a permanent depression. This is why Kramer even describes her as healed, because she "no longer met a doctor's criteria of depression' ([9]: 4). At this point, one could say, the part of Kramer's story that deals with Tess' therapy ends and a new part of the story starts, dealing with her psychotherapeutic enhancement, although Kramer still tries to make sure that a potentially masked depression does not return ([9]: 6).

In a second step, Kramer prescribes Prozac, enabling her to take a higher dose of medication to 
prevent her from falling back into depression. As he states: 'My goal was not to transform Tess, but to restore her' ([9]: 7). However, what happens can only be described as a transformation of her personality:

I have never seen a person's social life reshaped so rapidly and dramatically. Low self-worth, competitiveness, jealousy, poor interpersonal skills, shyness, fear of intimacy-the usual causes of social awkwardness-are so deeply ingrained and so difficult to influence that ordinarily change comes gradually if at all. But Tess blossomed all at once. (p. 8)

After having taken Prozac, Tess' love relationships become satisfactory, and she remarks positive changes in her work-life as well. She becomes 'less conciliatory, firmer, unafraid of confrontation' ([9]: $8 \mathrm{f}$.). Even more importantly, she breaks free from her overly-tight family relations. The 'relation towards those she watched over changed,' as Kramer puts it. She did not 'feel heightened responsibility for the injured' anymore and 'moved to another nearby town, the farthest she had ever lived from her mother' ([9]: 9).

Like numerous other patients, Tess experiences her 'loss of seriousness,' as she puts it, as a 'relief' ([9]: 9). Her recovery continues, and finally Kramer takes her off the drug. However, after a few weeks off medication, Tess asks him to prescribe her the drug again, explaining that she is not herself anymore without it. She perceives her 'old self' under which the symptoms of social awkwardness and depression prevail as 'ill,' and not as her true self.

Tess had become to understand herself-the person that she had been for so many years - to be mildly ill. [...] She did not feel herself when the medicine wore off and she was rechallenged by an external stress. [...] On imipramine, no longer depressed but still inhibited and subdued, Tess felt 'myself again'. But while on Prozac, she underwent a redefinition of the self. Off Prozac, when she became again inhibited and subdued [...], she now felt 'not myself'. Prozac redefined Tess' understanding of what was essential to her and what was intrusive and pathological (p. 19).

At this point, it is time to sum up the theoretical results. On Prozac, Tess says that she feels authentic; she feels like herself for the first time in her life. Without medication, Tess falls back into a state that she describes as not being herself. These consequences of the intake of Prozac seem to be the same for numerous other patients as well ([9]: 21). Accordingly, 'authenticity' means being able to focus on the essential things in life and on selfrealization. No longer hampered by social anxieties, patients such as Tess build up promising relationships with others and find meaning in life. Authenticity, in this sense, has an existentialist dimension: Prozac allegedly provides some insights into the meaning of life for those who take it. It helps them experience what they regard as their true selves. However, it is worth noting that Kramer describes the process as one of a 'redefinition' of the self ([9]: 19). This means that the socially competent and cheerful self that is prevalent under Prozac is declared as the 'real self,' whereas the less welcome, shy and depressed one, is not experienced as real anymore. One could say here that what is experienced is not a simple revelation, but a transformation into a better or even 'ideal' self, which is accordingly interpreted as the true one. In this sense, Prozac maybe called an authenticitygenerating drug. It can 'shape our understanding of the authentic self' as Kramer puts it ([9]: 20) and, equally importantly, it makes the perception of the authentic, ideal self perceivable as a phenomenally felt quality. This capacity to bring about felt authenticity may explain why Prozac is so popular and in such high demand.

Under Elliott and Kramer's application, the concept of 'authenticity' seems to be a vague umbrella term, embracing personal identity over time, autonomy, originality, self-knowledge, as well as self-realization, and even self-transformation toward the ideal self. ${ }^{2}$ Carl Elliott points out a puzzle of authenticity: How can a person be provided with a more authentic self by means of artificial enhancement devices? One hesitates to count those features and emotions that emerge suddenly within 2 weeks just by ingesting a pill as authentic. The idea that artificial devices can reveal a person's authentic selfhood seems repugnant.

These and similar concerns have been expressed recently by David Pugmire [10]: 111. Pugmire is one of the authors who caused emotional authenticity to become a key notion in emotion theory in the philosophy of mind and moral psychology, revealing a debate on emotional truth, emotional integrity, and emotional authenticity (see, e.g., De Sousa [10-17]).

\footnotetext{
${ }^{2}$ For a classical discussion of the term 'authenticity' cf. Trilling [42].
} 
Pugmire emphasizes the natural or artificial origin of an emotion. Some bio-conservative authors also take such an approach in the current ethical debate on enhancement. ${ }^{3}$ For them, an artificial means necessarily leads to an inauthentic result. In their eyes, those who take psychotropic drugs and employ other technical devices necessarily end up in an inauthentic emotional state. These feelings of repugnance toward technical interventions raise the concern about the proper reference system. What is the natural state with which an artificial means interferes? To find an answer to this and to similar questions, the time has come to examine the assumed naturalness and artificiality of emotional states.

\section{Natural and Artificial Emotions}

The main question in this paper is: Do artificial means like the antidepressant Prozac necessarily lead to inauthentic emotions? An appropriate answer requires further clarification of what inauthentic emotions could be and how they are connected with emotional artificiality. Some of the interdisciplinary approaches to emotion theory reveal a nature-nurture debate on emotion. Culture-relativist and socioconstructivist accounts are opposed to somatic and biologist definitions of what an emotion is. ${ }^{4}$ The latter claim that there are at least some innate emotions. Nevertheless, it proves to be problematic to apply the term 'natural' to innate emotions and the term 'artificial' to those that are more culturally shaped or more complex. It remains unclear in which respects these 'higher' emotions are more 'artificial' than the more basic ones. It seems that the dichotomy of 'artificiality' versus 'naturalness' does not really fit the nature-nurture debate on emotion.

What then is an artificial emotion? There are at least two different meanings for the adjective 'artificial.' In

\footnotetext{
3 The most well-known proponents of a bio- or valueconservative position in the enhancement debate are perhaps Habermas [18], Fukuyama [19], and the authors of the President's Council on Bioethics, especially Kass et al. [20]. The label 'bio-conservative' is used here to describe a position that opposes technological optimism and transhumanist ideas with regard to the enhancement of human nature. Parens' [21] position is a more well-balanced point of view. In what follows, I will simplify the conservative perspective and focus on Kass et al., who lay an emphasis on the use of psychopharmacology. ${ }^{4}$ For an overview of the nature-nurture debate of emotion, see Prinz [22], 103-160 and cf. Harré [39] and Roettger-Rössler [41].
}

general, one can distinguish the process by which an object or state is produced from the character or structure it actually has at a given point in time ([23]: 179-180, 2006: 234). One can accordingly distinguish between an adverbial and a predicative sense of the word 'artificial.' Taken in an adverbial sense, the word refers to the process or modus of the generation of an entity or state (cf. [23]: 179). In a predicative sense, in contrast, it refers to the intrinsic qualities and the character of an entity or state. ${ }^{5}$

What then is the adverbial aspect of the term 'artificiality'? What is an 'artificially induced emotion'? Does listening to Mahler's music, to take an example by Ronald De Sousa [25], lead to artificial emotions? Similarly, does drinking a glass of wine ([26]: 311)? There are no clear demarcation lines between natural and artificial devices or substances. The recent psychopharmacological enhancement inventions are based on an intimate knowledge of brain processes. Thus, the adverbial sense of the term 'artificiality' and the meaning of 'artificially induced emotion' are becoming more and more doubtful.

One can, of course, raise the objection that one could come up with several distinctions between, for example, changing one's state of mind via listening to Mahler's music and ingesting a pill, the former being a more active process and the latter a more passive one. However, as soon as one asks what follows from such a distinction between natural and artificial means, it is to be assumed that the distinction does not necessarily correspond to a moral distinction.

Turning to the predicative aspect of artificiality, does the demarcation line prove clearer? Is there something like the perceptible artificial quality of an emotion? For authors such as Achim Stephan [26], the answer is yes. In a thought experiment, Stephan pictures a way to refer to what could be called the qualitative artificiality of an emotion: A chemical laboratory creates substances that trigger entirely novel emotional experiences, that is, emotions no one has ever felt before. These new emotions, Stephan [26]: 311 claims, could rightly be called

\footnotetext{
${ }^{5}$ Hence, the intrinsic character of an artificial flavour can be called nature-identical. Correspondingly, there may be artificially produced emotions that are nature-identical in the way the subject experiences them. Similarly, the hormone oxytocin can be produced artificially, exposing a nature-identical structure and experience ([24], 673-676).
} 
artificial ones. What he means by this is that these emotions are artificial in a predicative sense.

There are good reasons, however, to argue that artificiality is not a felt quality of an emotion. It seems impossible for an emotion to have an artificial character once it is perceived. It is important to note that the feelings people on Prozac undergo are not experienced as artificial. ${ }^{6}$ They are artificial in the adverbial sense, but not artificial in the predicative sense. From the first-person perspective, the artificially induced emotions under Prozac cannot be distinguished from natural emotions. Patients on Prozac say they do not feel drugged at all, but feel perfectly sober and clearheaded, whereas earlier antidepressants such as tricyclics or MAOIs usually made them feel drugged ([9]: 66).

However, the claim that emotions cannot have an artificially felt character is not limited to the effects of Prozac. Rather, I support the more general, conceptual thesis that people do not experience artificial emotions when taking drugs of whatever kind. It is certainly not possible to feel the origin of an emotion once it is perceived. Either a person has a certain feeling, or he or she does not have it. Once it is there, the person can no longer distinguish how it is brought about. Say someone has given Peter a drug that is supposed to make him feel proud, and say that the feelings produced by it differ qualitatively from his normal feelings of pride. In this case, what Peter feels after the intake of the drug is not artificial pride, but no pride at all. It must be something else, and the utmost he can say is that what he feels might resemble

\footnotetext{
${ }^{6}$ Cf. Kass et al. [20]: p. 250 f.: A young man who, under the influence of Ecstasy, proposes to a young girl unknown to him, really experiences his feelings of love in that moment without attributing an artificial quality to it. As Kass et al. as proponents of the bio-conservatives put it: 'Imagine that a young partygoer, under the influence of the drug, tells a young woman that he loves her and wants to marry her. Imagine also that he means it, insofar as the feeling he now has is indistinguishable from what he might one day feel when he truly falls in love with a woman. Should the fact that his feelings are produced by the drug, rather than inspired by the woman, matter? It should of course matter to her. His drug-based professions of love cannot be taken seriously. Neither should a marriage proposal that owes everything to his being 'high.' But it should also matter to him, once he awakens from the 'alternative reality' induced by taking Ecstasy and recovers the real identity that the drug temporarily erased.' In this vein, bio-conservative authors raise doubts about the authenticity and normative integrity of emotions triggered by artificial means.
}

feelings of pride. Vice versa, if the drug successfully brings about the feeling of pride in him, he does feel proud, and nothing else.

Still, there seems to be one special thing about Prozac in this context: People who took earlier antidepressants usually felt drugged, whereas this is not the case for Prozac. Therefore it can be assumed that people under earlier antidepressants had good reasons to cognitively doubt the feelings they experienced under the drug because they felt as if they were no longer in a normal state of mind and body at all. Accordingly, they perhaps were inclined to reflect on the history of their feelings under the drug and to begin to experience them as inauthentic. ${ }^{7}$ On the contrary, what Prozac seems to bring about is a feeling of authenticity, i.e. a feeling that the emotions a person has while taking it are his or her ideal feelings he or she identifies with. There are no good reasons for this person to cognitively doubt the authenticity of these emotions - on the contrary. He or she embraces them as the true ones. This means the person has no reason to reflect upon their natural or artificial origin of her emotions under Prozac. If Peter is taking Prozac and consequently feels proud, he feels proud, no matter how this emotion was brought about.

To sum up, it only makes sense to use the terms 'artificial' and 'natural' in the adverbial form of 'naturally produced' or 'artificially induced,' but not in the predicative sense of 'perceived as natural' or 'perceived as artificial.' Thus, it does not make sense to talk about natural and artificial emotions at all as far as their felt quality is concerned.

Because Prozac was created in the laboratory, it is, of course, an 'artificial' substance, interfering with the 'natural' serotonin level in the brain. Does this necessarily imply that the resulting emotions are artificial as well? As mentioned before, the concepts of natural and artificial emotions are problematic. It hardly makes any sense to ask whether an artificial means leads to an artificial emotion. Instead, a more appropriate question might be: 'Do artificial substances lead to inauthentic results?' Therefore, in the

\footnotetext{
${ }^{7}$ Later on this article, I will argue that the reflection on the rationality and coherence of his or her emotions can lead a person to begin to doubt his or her own emotional experience and to perceive his or her own emotions as inauthentic. I will call this the 'repercussions' of the standard of rationality and coherence on the standard of authenticity.
} 
following, the connections between the concept of naturalness and the notion of authenticity will be pointed out.

It proves helpful to consider a thought experiment by David Pugmire dealing with some drug-induced, 'artificial' emotions as well. In his paper entitled 'Real Emotion,' David Pugmire [10]: 105 ff supports a concept of emotional authenticity that is committed to the 'origin' of an emotion. He develops a thought experiment on a drug, Amity, which brings about amicable feelings between human beings. The coworkers Nick and Rick are constant quarrelers, and do not get along with each other very well. After taking the drug Amity, however, they immediately start to like each other, or at least begin to tolerate each other's behavior.

Following David Pugmire's argument, it is impossible that an artificial means leads to authentic results. A drug can never bring about an authentic emotion. This at least holds for more complex feelings like affection and love. ${ }^{8}$

In the imagined case of Nick and Rick, genuineness was seen sometimes not just on content (how one felt) but on causal history (how one came to feel that way). There, the integrity of some emotions was undermined if they originated in pharmacology rather than in appraisal. (p. 111)

For David Pugmire, there is a causal relation between the genesis and the intricate value of an emotion. This is because for Pugmire, authentic emotions always imply certain beliefs and cognitive appraisals of a situation. As he puts it, 'real emotion demands actual belief' ([10]: 116): ${ }^{9}$ A person is experiencing true fear only if he or she believes that there is a real reason to be afraid ([10]: 109).

Following this line, it is impossible for someone to love another person wholeheartedly if he or she thinks the other one is not a good person and worth loving. The affection between Nick and Rick on Amity is not an authentic emotion, according to David Pugmire.

\footnotetext{
$\overline{{ }^{8} \text { Pugmire [10] }}$, p. 108 distinguishes less complex emotions ('feelings') from more complex emotions ('affects'). Affection may not be reduced to a mere feeling. Rather, it embraces rational reasons and appraisals.

${ }^{9}$ But see also Pugmire [10], p. 121: 'Emotion needn't follow insight.' It is not entirely clear here to which extent Pugmire applies rationalist standards to emotions.
}

Instead, he calls their respective emotions 'factitious' ([10]: 111), because they are not based on actual changes of beliefs. Therefore, for David Pugmire [10], a technically and voluntary manipulated emotion is not authentic:

One cannot do much to give the desired emotion a chance, but then it just has to happen, as by grace, or not. And there's no cutting the risk that it won't by attention-management or other selfmanipulation. There are some emotions one cannot intend to induce in oneself. Technique cannot replace uncertainty and hope. A certain integrity must be granted even to 'bad' emotions. [...A] certain passivity or receptivity towards emotion is a necessary virtue. This prospect has always been unwelcome to those who need to exert total control over their lives. (pp. 119-120)

There is an implicit tension in this attitude. On the one hand, Pugmire seems to claim that resilient and arational emotions are necessarily inauthentic. If individuals undergo an emotional experience that is at odds with their rational conviction, they have an inauthentic feeling. ${ }^{10}$ On the other hand, for Pugmire, emotions are obviously internally arational, or at least avolitional, because they represent the very limits of the rational and volitional capacities. They indicate those realms of life that evade full control. ${ }^{11}$ To a certain degree, emotions are characterized by this feature of rational uncontrollability. There are authentic emotions that are arational or even irrational. This, however, makes Pugmire's approach implausible. According to him, artificially manipulated emotions are necessarily inauthentic because they are sometimes irrational. But as we have seen, being irrational does not distinguish these emotions from nonmanipulated emotions that maybe arational or irrational 'by nature.'

In light of the above-mentioned problem of artificiality and naturalness, one could raise the following objection to Pugmire's account: In his

\footnotetext{
${ }^{10}$ Rescher ([27], 211 ff.) even suggests 'two modes of happiness,' distinguishing 'affective happiness (pleasure)' and 'reflective happiness (rational contentment).'

${ }^{11}$ Pugmire does not refer explicitly to Martha Nussbaum here, but it seems that something comes into play that Nussbaum [28], 43 understands as the crucial function of emotion to indicate a person's helplessness, vulnerability, attachment, and mortality.
} 
analysis, biological causes ('origins') are inextricably mixed with a person's phenomenal consciousness ('felt authenticity') on the one hand and the logical space of reasons ('irrationality' of an emotion) on the other.

Picking up the case of felt authenticity, when addressing Stephan's thought experiment, one could argue that the authenticity of an emotion cannot refer to its 'natural' origin. There are emotions of artificial origin that feel 'nature-identical' or even authentic. There is no necessary causal link between the artificial origin of an emotion on the one hand and its felt inauthentic quality on the other.

It seems that David Pugmire's considerations fall short of explaining why an artificial origin (e.g., technical means and enhancement strategies) can engender only inauthentic emotions. Unnaturalness of genesis is not a sufficient condition for the inauthenticity of the felt quality of an emotion.

In most of Peter Kramer's cases, Prozac resembles Amity in several crucial respects. In one of his case studies, the perfectionist working mom Julia becomes easy to get along with under Prozac. She turns into an understanding and loving partner to her husband and children despite their little imperfections. After having taken Prozac, Julia has no good reason to doubt the integrity of her emotions. She feels relieved because she can cope better with her everyday life, and her family is happy about the improved situation. Julia even feels more authentic than before; she feels more 'like herself' because she now has the 'right feelings' to identify with ([9]: 22-40).

Prozac does not lead to inauthentic emotions, although these emotions are artificially induced. There is no necessary causal connection between the artificiality of the means and the inauthenticity of results. Accordingly, it does not make sense to refer to the natural or artificial origin of an emotion if one aims to assess its authenticity.

\section{A Non-Naturalist Approach to the Authenticity of Emotions}

Naturalness and artificiality are not perceptible states, whereas authenticity is. Therefore, in what follows, the term 'authenticity' will be reserved for the level of qualitative perception. Here is a preliminary account. From the first-person perspective, the authenticity of emotions is a phenomenally felt quality. 'Phenomenally felt quality' refers to the way a person experiences his or her own emotions. However, it could be the case that the experience is clearer in the negative case of inauthenticity, i.e. when a person is of the opinion that he or she is far away from his or her true or ideal self, having emotions he or she does not identify with. Since it is notoriously difficult to describe what it is like to feel authentic, it might even be easier to fix the negative feeling of inauthenticity, which is sometimes described as alienation and which is a common term in the philosophical literature.

A possibly more appropriate way to argue could be to say that the 'feeling of authenticity' is something like a second order emotion, revealing whether a certain other emotion is authentic or not. However, this raises the concern of whether such a second order emotion is an emotion proper, or rather an evaluative cognitive judgment. Still, at least as far as Peter Kramer's patients describe it and as it is mentioned in the reports of his patients, the experience of emotional authenticity seems to be more a felt state than a thought.

In this vein, however, it is to be asked why authenticity should be a felt quality, whereas naturalness is not, and the same for inauthenticity and artificiality. Again, with reference to the enhancement literature quoted above, the emotions under Prozac are not experienced as artificial in character; neither are they for other drugs. In the case of Prozac, we can explicitly state that the experiences even seem to boil down to experiences of authenticity, while not of artificiality ([9]: 66). As already mentioned, what counts here is that the emotions felt under drugs in general are not experienced as artificial. Rather, once a person has an emotion he or she can no longer distinguish how it came about. Otherwise, he or she does not really have that emotion, but another one.

In what follows, I attempt to reconstruct a notion of emotional authenticity that is in accordance with the assessment by Peter Kramer and Carl Elliott. Following the main thesis of the paper, emotional authenticity is to be regarded as a phenomenally felt quality. The notion 'emotional authenticity' thus means the phenomenally felt quality that a person perceives with respect to his or her inner emotional state, no matter by which means (natural or artificial) it has been brought about. The main argument of this paper claims an emotion to be authentic if the individuals experiencing it recognize 
their own feelings really as their own and identify with them. This goes back to the above-mentioned claim that each and every emotion is authentic if it is recognized as such by the subject.

In everyday life, it seems that many people find it important that their own and other people's emotions are authentic. This can be inferred from the widespread use of enhancement drugs such as Prozac, because according to Peter Kramer and Carl Elliott, especially those people seem to use it who strive for emotional authenticity. In this vein, the notion 'emotional authenticity' turns into a normative term: Emotional authenticity is something that people want to experience and which they think they themselves and others should experience. 'Normativity' in this context is necessarily related to the first-person perspective of those who experience authenticity. It does not refer to objective values, but to what is perceived as valuable or desirable in a normative or evaluative sense.

However, as the material gathered by Kramer and Elliott shows, 'emotional authenticity' might not be the only concept that people recur to when normatively assessing their emotions. Emotional authenticity alone might not be the ultimate standard of what people demand from their emotions. Rather, in everyday life, many people seem to find it at least equally important that a person's emotions are rational and coherent rather than authentic. In what follows, these other two standards, the one of emotional rationality and the one of emotional coherence, will be examined.

The rationality standard of emotions is concerned with the epistemic fittingness of intentional object and feeling. An emotion is regarded as rational if it represents a state of affairs correctly or at least grasps it in a rationally comprehensible way. ${ }^{12}$ This requires a

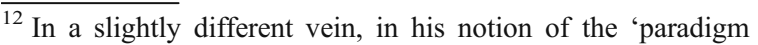
scenario,' De Sousa [12] captures the idea of the rationality of emotions. Paradigm scenarios 'are drawn first from a daily life as small children and later reinforced by the stories, art, and culture to which we are exposed. Later still, they are supplemented and refined by literature and other art forms capable of expanding the range of one's imagination of ways to live. Paradigm scenarios involve two aspects: first, a situation type providing the characteristic objects of the specific emotion-type (where objects can be of the various sorts mentioned above), and second, a set of characteristic or "normal" responses to the situation, where normality is determined by a complex and controversial mix of biological and cultural factors.[ .....' [29] This idea implies that we regard a person's emotions as rational if we can trace back the paradigm scenario from which they stem.
}

cognitivist approach. A recent, phenomenologically modified version of cognitivism stems from Peter Goldie [30]. Goldie regards an emotion as a 'feeling toward something,' that is, as a felt quality that is directed intentionally toward an object or state of affairs. The first aspect of an emotion, according to Goldie, is a 'feeling.' It is the perceived aspect from the first-person perspective. The second aspect of an emotion is its intentional content, that is, the object or state of affairs toward which it is directed. Emotions differ from mere moods and bodily feelings by pointing toward something and thus meaning something. ${ }^{13}$ It is important to note that for Goldie, the two aspects of an emotion do not fall apart into two components, but form a single unit. Following Goldie's ([30]: $10 \mathrm{ff}$.) argument, it is possible that the intentional content can be communicated to other people.

Peter Goldie does not deduce any stance of rationality from his account of an emotion that could be used to explain when an emotion is authentic and when it is not. But his model opens up this possibility. An emotion is rational if the relation between qualitative feeling and intentional content is harmonious. In the case of an irrational emotion, however, the relation between the felt quality on the one hand and the intentional object on the other hand is disharmonious. ${ }^{14}$ An emotion is rational if there is no major discrepancy between both its aspects. Here is an example for an irrational emotion in the sense of a lack of rationality. In terms of the propositional content of an emotion, a man is convinced that a little dog sitting before him is definitely not dangerous (Nussbaum 2001): 35. Nonetheless, he experiences strong feelings of fear. In this case, there is a discrepancy between the qualitative aspect of his emotion (intense fear) and its intentional content (his cognitive-rational conviction that the object is not dangerous). The emotion is not only arational as most emotions are, but utterly irrational.

Occasionally, taking drugs can result in such a gap between both aspects of an emotion, but this cannot hold as a rule. Vice versa, there may well be a discrepancy that is not caused by the consumption of drugs. ${ }^{15}$

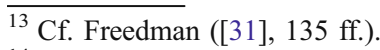

${ }^{14}$ Cf. Salmela ([16], 205 ff.).

${ }^{15}$ Cf. D'Arms and Jacobson [32] for an analysis of recalcitrant emotions.
} 
The rationality of emotions is a sociocultural category, implying an idea of rationality that is embedded in the respective culture. ${ }^{16}$ 'Sociocultural' means the way a certain emotion is interpreted by a group of persons or by society at large that implements certain standards of rationality. In this vein, a person's emotional authenticity cannot be assessed exhaustively by self-reference because, to some extent, everybody is socialized into a cultural context and embedded in it, time and again being confronted with the opinions of others who implicitly or explicitly assess his or her emotional life.

The third standard that sometimes is applied to emotions deals with the coherence and consistency of an individual's history of emotion over the course of time. ${ }^{17}$ An abrupt change in an individual's emotional life will make a new emotion appear as doubtful. If individuals have been gentle and compassionate all their lives, people around them will have good reason to doubt the authenticity of their emotions if they suddenly behave in a ruthless, overbearing, and aggressive manner. ${ }^{18}$

One could perceive a jolt, a discontinuity between their new and old emotions. Some narrative theories of emotion take account of these phenomena of discontinuity. For instance, Robert C. Solomon ([33]: $24 \mathrm{ff}$.) points out that the reader recognizes when a story is not told well in terms of the coherence of a fictitious character's emotional life, and chides the author's lack of psychological finesse. The same seems to hold for real life.

\footnotetext{
${ }^{16}$ Salmela [16] 225 ff. also emphasizes the importance of cultural norms when employing the example of Huckleberry Finn.

${ }^{17}$ For an other accounts of criteria of emotional authenticity, see Salmela [16] about subjective perception, rationality, and coherence. For Salmela, 'coherence' is the coherence of one's emotions 'with one's rational values and beliefs,' i.e. the coherence between 'first- and second-order emotions and evaluative judgments' ([16], 210, 222). His term 'coherence' thus comes close to what in this paper constitutes the standard of rationality. Further, Salmela mentions a state of an emotion being 'psychologically real' (224), but it seems that for him this is not a criterion of authenticity in its own right. His account neither goes back to the artificiality and naturalness of an emotion, nor to the enhancement debate. The same holds for Salmela's analysis of emotional truth [17].

${ }^{18}$ This holds at least if changes cannot be traced to, for instance, a (traumatic) event etc. If there are reasons for change, we accept quite sudden, holistic transformations.
}

Whereas the first standard applied to emotions (authenticity as a phenomenally felt quality) can usually only be applied by the individual that experiences a certain emotional state, the other two stances, rationality and coherence, can additionally be applied from the first- and the third-person perspective.

It is difficult to see which of the standards (authenticity, rationality, and coherence) is the most important one and how they hang together. What is important to note, however, is that the standard of authenticity seems to be independent of the one of rationality and of coherence. A person can experience authentic feelings in the qualitative sense even if his or her feelings appear as irrational and incoherent. In contrast, the application of the rationality and the coherence standard can in certain cases have repercussions on the ascription of emotional authenticity. For instance, it could be that individuals begin to experience their emotions as inauthentic once they apply the standards of rationality and coherence to them. The standards of rationality and coherence, once mapped to a person's own emotions, can lead him or her to reconsider his or her seemingly authentic emotions, and finally even to perceive them as inauthentic. Once individuals recognize their own new emotions as irrational and incoherent with respect to their other emotions, they eventually begin to distance themselves from their own emotions and to feel alienated from them, rather than experiencing them as authentic anymore. From the perspective of others, it could be that the alleged irrationality and incoherence of a person's emotions eventually leads to doubts about their authenticity. However, this connection between the three standards is certainly not always extant.

To sum this up: According to the main argument of this paper, each and every emotion is regarded as authentic as long as it is perceived as such, no matter whether it accords with the standards of rationality and coherence or not. As far as all three standards are concerned, it is essential to see that the biological function of the human body is not a subject of discourse. Authenticity is not a biological category but a phenomenological one. Similarly, rationality and coherence are not biological, but epistemological and socio-cultural standards. Their application to emotions works without referring to an allegedly 'natural' or 'unnatural' bodily state and the way it is brought about or manipulated, be it by artificial means or not. 
This is why emotional authenticity, along with emotional rationality and coherence, is regarded here as a non-naturalist notion.

\section{Some Critical Remarks}

Having said this, it turns out that emotions under Prozac sometimes fail to meet the three standards. Let us first have a look at the standards of rationality and coherence.

Carl Elliott [2]: 74 tells the story of a Japanese clerk. She used to be a shy person who under Prozac loses her social anxieties. But she also loses all inhibitions and the due respect to be paid to her boss and co-workers. Eventually, she decides to serve cocktails at a dinner party for her company wearing only a negligee. Prozac has made her lose her anxieties to an unreasonable extent. As long as the clerk experiences her own emotions as authentic, there is no reason to negate their authenticity. However, her new behavior and her new emotions no longer fit her own lifelong rational conviction that it would be better to pay due respect to the members of her company - a conviction also shared by her social environment. If we take the rationalist standard to be valid, this is a clear case of emotional irrationality and also of incoherence, although not of inauthenticity.

It is difficult to normatively assess this case as well as similar cases. On the one hand, from a prudential point of view, one would hope on the clerk's own behalf that she stops taking Prozac, because it changes her emotions and her attitude in a way that endangers her professional career and appalls others. On the other hand, for instance from a therapist's point of view or from the perspective of a friend or a socio-critique, one could welcome the idea that she has started to break free from societal constraints and to lead a more authentic life in which she fearlessly lives out her own feelings and does not care so much about the opinion of others anymore. Maybe her new emotional capacities provide her with a fresh perspective on her work life which she might have experienced as alienating even before she had taken Prozac.

Seen from another point of view, people on Prozac can also have the 'wrong feelings' understood in an epistemic way. As Peter Kramer ([9]; cf. [2]: 74 ff.;
[34]: 29) puts it, quoting from his interviews with patients:

People on Prozac sometimes say that they no longer experience grief, anxiety, or sadness quite so deeply. Occasionally they will realize that circumstances call for sadness - that they are expected to share in another person's grief, or that they should worry about their financial problems - but they are unable to call up the appropriate emotional reactions. [...] It can be 'hard to worry about anything' while taking Prozac 'because nothing matters.' (p. 258)

In this sense, the emotions of these people under Prozac are still authentic, but not rational anymore. Seen from a common-sense, normative point of view, the intake of the drug can lead to a situation in which a person loses the connection to his or her social environment and in which his or her financial situation becomes precarious.

However, there are not only examples in which Prozac leads to irrational and incoherent feelings, but also some in which it can even lead to inauthenticity, i.e. in which the emotions a person undergoes no longer meet the standard of authenticity as a phenomenally felt quality. An example is Kramer's patient Philip. Paradoxically, taking Prozac is painful for him. He considers that feeling well means to be in a state of self-deception and inauthenticity. While on Prozac, Philip is at first glance 'happy.' On the other hand, as a second-order feeling, he realizes that there is something wrong with his happiness. He feels it to be inappropriate in light of his personal history as a troubled youth. Peter Kramer [9] points out:

His moodiness and irritability were comfortable to him, because they represented his legitimate suffering and rage. [...] On Prozac, Philip felt better than well, and he hated it. He had been prematurely robbed of his disdain, his hatred, his alienation. [...] The six months of feeling fine were hell for Philip. He felt phony; he did not trust himself. (p. 291)

Here, enhancement is accompanied by inauthenticity in the very sense described in this paper. Philip experiences his own emotions as inauthentic. Interestingly, one could also reconstruct his feeling of alienation from his own emotions under Prozac as his recognition of the fact that they lack rationality and 
coherence. By running around with a smile on his face, Philip feels inauthentic, because his actual happiness does not correspond with the true state of affairs, that is, his deep inner embitterment and melancholy. As Kramer [9]: 258 puts it: 'He was truly relieved to stop the medicine and resume his bitterness.' At least from Philip's own perspective, he perceives his own positive feelings as inauthentic because he experiences them as irrational and incoherent with his emotional history. ${ }^{19}$ Here, the standards of authenticity, rationality, and coherence seem to merge, at least from a first-person perspective. However, the normative question is again a tricky one. Maybe an outsider would assess Philip's newly gained happiness as a preferable state of mind, even if he or she realizes that Philip feels inauthentic, and would regard his perceived lack of rationality and coherence as not especially worrisome. This shows that all three standards and their normative consequences are open to interpretation and depend on the values of those who apply them.

On an even more general level, one could object that the standard of coherence can not properly be applied to emotions. Why should it for instance be regarded as problematic if a person altered his or her emotional life? At least a person's emotional attitudes could be changed to the positive, and there is a plethora of literature on personal conversions and their positive moral impact. A possible answer to the question of why one could still regard a lack of coherence as objectionable is twofold. First, it has been a philosophical commonplace since John Locke and throughout biomedical ethics that threats to diachronic personal identity are usually regarded as problematic. The reasons for this have partly to do with traditional religious concerns that the integrity of a person's soul could be endangered, and in a more mundane way that a person's autonomy could be put at risk when personal identity is at stakeautonomy being a widely accepted ethical notion. ${ }^{20}$ The discussion of this goes beyond the scope of this paper. Second, and more importantly here, it seems that emotions are what they are, i.e. are individualized and defined as what they are, because they are

\footnotetext{
${ }^{19}$ Very much in the line of the main thesis of this paper, Kramer does not present Philip's doubts as feelings of 'unnaturalness.'

${ }^{20}$ Kramer [9]: 265 however, states: 'My impression is that Prozac $[\ldots]$ generally increases autonomy.'
}

embedded in a nexus of other emotions. Each emotion is embedded in the nexus of emotional attitudes a person has developed during his or her lifetime in the sense of an emotion interacting with other emotions and depending on them. For example, a person who under the influence of an enhancement drug loses the ability to feel fear might lose other emotional abilities as well, such as to emotionally experience importance and moral salience. This alone does certainly not amount to any evidence for the claim that discontinuities in a person's life are always normatively problematic. However, it hints to the possibility that enhancement drugs that alter people's emotions can lead to unexpected and uncontrollable changes in their personalities which, in turn, might have the described normative implications for their identity and autonomy. At the end of this paper, I will come back to this point when discussing happiness and sadness as emotions that gain their meaning from being embedded into a person's diachronic emotional life.

Obviously, the new enhancement of emotions has to be assessed critically, because it bears severe risks and dangers. In the face of the current expansion of the enhancement market, we need instruments to assess their normative implications or even ethical intricacies. This is why the above-mentioned nonnaturalist standards of authenticity, rationality, and coherence could enable us to decide which acts of enhancing emotions are normatively doubtful. I therefore think that authors like the 'transhumanist' Nick Bostrom who uncritically support the enhancement of emotions via technological means neglect the complexity of our emotional life and of its inherent normativity. He simply aims at creating 'healthier, happier, wittier people,' as he puts it. ${ }^{21}$ In his paper 'Human Genetic Enhancements: A Transhumanist Perspective,' where he explores the 'posthuman realm' of enhanced human beings, Bostrom states:

The range of thoughts, feelings, experiences, and activities that are accessible to human organisms presumably constitute only a tiny part of what is possible. [...] It is not far-fetched

\footnotetext{
${ }^{21}$ Cf. Bostrom [35]: 498. For a more nuanced, but still problematic account, see Bostrom [43] in Medical Enhancement and Posthumanity, eds. Bert Gordijn and Ruth Chadwick (Springer, 2008): pp. 107-137. For a critical stance, see Healy [36] and Klerman ([37], cit. in Kramer [9]: 277).
} 
to suppose that there are parts of this larger space that represent extremely valuable ways of living, feeling, and thinking. We can conceive of aesthetic and contemplative pleasures whose blissfulness vastly exceeds what any human being has ever experienced. [...] We can imagine love that is stronger, purer, and more secure than any human being has yet harbored. (p. 495)

Bostrom's underlying account of how our emotional life is structured and how it could be 'improved,' however, seems to be an oversimplifying one. Bostrom suggests that emotional sensitivity and the range of positive emotions should just be increased and amplified via technical means like emotion intensifying drugs, brain implants, and genetic interventions.

Against Bostrom's technological optimism, there are, however, some severe ethical and moral concerns to be raised as our emotional life becomes increasingly subject to technological feasibility. Changing our emotional life means changing our cultural and epistemic norms and our standards of rationality. The systematic use of psychopharmacological enhancement in a society does not change individual emotions of individual persons only, but always has a deeper impact on society and even 'human nature' as such. Especially emotional enhancement has consequences on our rational and moral judgments. Following Martha Nussbaum [28]: 19 ff. and others, emotions play a significant role in 'judgments of value and importance.' For instance, Carl Elliott ([2]: 49, cf. Kramer [9]: 269 f.) points out that in American culture, the adequate time of mourning over the death of a loved one is not supposed to exceed 1 year. If depression continues beyond this period, the mourning person is advised to see a doctor and get medication, which in some cases might put pressure on him or her to finish their mourning 'prematurely.' In contrast, in more rural societies like Greece, it is still considered 'normal' to mourn for 5 years or more - which in turn can, of course, put pressure on those who don't feel sad for such a long time. There is certainly no absolutely appropriate time to mourn. Rather, the standards seem to be culturally relative. What is important here, however, is that Bostrom seems to overlook how deep enhancement strategies can alter our human self-understanding and our perception of values. The mere existence of effective antidepressants can alter the status and the dignity of existential human experiences such as the capacity to mourn extensively for a dead person and to feel compassion for those in mourning.

This refers equally to the standards of rationality: If our cultural standards and judgments about what is a 'rational' period of mourning shift because means are available to drastically shorten it, our very standards of appropriateness between feeling and object may change as well. Not only in the epistemic, but also in the normative realm, major changes are to be expected with reference to the applied standards of appropriateness and authenticity of emotions themselves.

Furthermore, sometimes our emotions expose considerable intelligence and rationality, and therefore should not be changed. Think only of the Japanese clerk: Prozac made her lose her anxieties to an unreasonable extent, and from a rational perspective, it would have been better for her to pay due respect to her colleagues ([2]: 74).

Last but not least, emotions obey laws of their own and form a coherent nexus. This idea refers to the third standard, the one of coherence. Most emotions are not 'enhanceable' in the same way cognitive features are. You can quantitatively enhance your memory performance and your IQ score. But enhancing well-being and happiness will run up against internal limits, due to the internal logic and nexus of emotions. $^{22}$ To illustrate this, here are a few remarks on the capacity of antidepressants to increase happiness. For instance, if a psychotropic drug increases happiness more and more, there may be a point at which happiness becomes too intense and suddenly turns into mere silliness. Furthermore, happiness is a contrast term. Only those who also know what sadness is can be happy in the true sense of the word. Happiness alone cannot be stretched over time without becoming shallow and stale. It loses its meaning if it does not have a counterpart. Due to the extensive use of antidepressants, one day we may become unable to feel sadness and deep melancholy any more. And this, in turn, means that we run the risk of forgetting the internal meaning of happiness

\footnotetext{
$\overline{{ }^{22} \text { Salmela [16] }}, 218$ also points out that Ronald de Sousa and Bennett Helm ([12], 324, [38]) deal with the interconnections of emotions with each other. Helm emphasizes that emotions 'impose rational commitments on each other.' As indicated before, Salmela's notion of coherence seems to be reserved for the coherence of emotions and beliefs.
} 
itself, which has its place in a complex nexus of other emotions. All future enhancement methods will have to carefully explore the complexities of emotions to avoid destroying their subtle authentic balance.

\section{Conclusions}

It transpired that in certain respects one could call Prozac an authenticity-generating drug. The perfectionist working mother Julia in Peter Kramer's case study feels more authentic than ever after having taken Prozac. So does the overly shy patient Tess who allegedly finds her true or ideal self thanks to the drug. There is no reason to doubt the achieved emotional authenticity of these and other patients who claim to have reached similar results. The overwhelming majority of patients described by Kramer feel authentic, the standard of felt phenomenal quality being fulfilled. Having 'authentic' emotions eventually helps them to experience full self-realization.

Therefore, in contrast to authors like David Pugmire and to bio-conservative authors in the enhancement debate, a person may well have authentic emotions or emotions of authenticity, even when they are induced artificially. The seemingly necessary causal link between artificial origin on the one hand and resulting emotional inauthenticity on the other does not prove valid. There are artificially induced authentic emotional states. And vice versa, there are naturally engendered emotions that turn out to be inauthentic.

What this paper has attempted to show is that emotional authenticity or inauthenticity cannot be inferred from the naturalness or artificiality of the devices employed. This is why the standard of the authenticity of emotions was declared a non-naturalist standard. The same holds for the assessment of emotional rationality and coherence. It is certainly true that, as the example of the patient Philip has shown, some patients may lose their emotional authenticity while on medication and others no longer meet the standards of emotional rationality and coherence. Nevertheless, this loss of emotional authenticity, emotional rationality, and coherence, again, has to be assessed by epistemic and sociocultural categories, not by biological ones. The most important insight of this article was therefore that the authenticity of an emotion seems to be independent of its natural or artificial origin.

On the other hand, the uncritical and unlimited enhancement of emotions via technological means as suggested by, for example, 'transhumanist' authors falls short of recognizing the complexity and subtlety of our emotional life. Obviously, the enhancement of emotions is a more sophisticated enterprise than the enhancement of cognitive performance, of athletic skills, or physical beauty. Our emotions depend on each other in a fragile nexus that can easily be destroyed by uncontrolled manipulation. It remains far from clear whether the simple enhancement of positive emotions such as 'happiness' or of emotional sensitivity and empathy would lead to a good and authentic life. In order to reject an uncritical technological optimism, we therefore need reliable intrinsic stances of emotional authenticity, rationality, and coherence to assess future strategies of the enhancement of emotions. Such a consideration, however, should leave simplistic bio-conservative ideas of the naturalness of emotions behind.

AcknowledgementsI wish to thank Oliver Hallich and an anonymous referee for their helpful comments and Mikko Salmela and David Pugmire for their remarks on an earlier draft.

Open Access This article is distributed under the terms of the Creative Commons Attribution Noncommercial License which permits any noncommercial use, distribution, and reproduction in any medium, provided the original author(s) and source are credited.

\section{References}

1. Kraemer, Felicitas. 2009. Neuro-Enhancement von Emotionen: Zum Begriff emotionaler Authentizität. In NeuroEnhancement: Ethik vor neuen Herausforderungen, ed. B. Schöne-Seifert, D. Talbot, U. Opolka, and J.S. Ach, 189220. Paderborn: Mentis.

2. Elliott, Carl. 2003. Better than well: American medicine meets the American dream. New York: Norton.

3. Elliott, Carl. 1998. The tyranny of happiness. In Enhancing human traits, ed. E. Parens. Washington: Georgetown UP.

4. Taylor, Charles. 1991. The ethics of authenticity. Cambridge Mass: Cambridge UP.

5. Juengst, Eric T. 1998. What does enhancement mean? In Enhancing human traits, ed. E. Parens. Washington: Georgetown UP.

6. DeGrazia, David. 2000. Prozac, enhancement, and selfcreation. Hastings Center Report 30(2): 34-40.

7. DeGrazia, David. 2005. Enhancement technologies and human identity. Journal of Medicine and Philosophy 30(3): 261-283.

8. Parens, Erik. (ed.). 1998. Enhancing human traits. Ethical and social implications. Washington DC: Georgetown UP.

9. Kramer, Peter D. 1997. Listening to Prozac: A psychiatrist explores antidepressant drugs and the remaking of the self. New York: Penguin. 
10. Pugmire, David. 1994. Real emotion. Philosophy and Phenomenological Research 54(1): 105-122.

11. De Sousa, Ronald. 2007. Truth, Authenticity and Rationality. Dialectica 61(3): 323-345.

12. De Sousa, Ronald. 1987. The Rationality of Emotion. Cambridge Mass: MIT Press.

13. De Sousa, Ronald; Morton, Adam. 2002. Emotional Truth. Supplement to the Proceedings of the Aristotelian Society, 76(1): 247-263.

14. Elster, Jon. 1999. Alchemies of the Mind. Rationality and the Emotions. New York: Cambridge UP.

15. Pugmire, David. 2005. Sound sentiments: Integrity in the emotions. Oxford: Oxford UP.

16. Salmela, Mikko. 2005. What is emotional authenticity? Journal for the Theory of Social Behaviour 35(3): 209230 .

17. Salmela, Mikko. 2006. True emotions. Philosophical Quarterly 56(224): 382-405.

18. Habermas, Jürgen. The Future of Human Nature. Oxford: Basil Blackwell (2003, German 2001).

19. Fukuyama, Francis. 2003. Our Posthuman Future. Delaware: Baker \& Taylor.

20. Kass, Leon R. et al. 2004. President's Council on Bioethics (ed.), Beyond therapy: Biotechnology and the pursuit of happiness. San Francisco: Dana Press.

21. Parens, Erik. 1989. Is better always good? The enhancement-project. In Enhancing human traits, ed. E. Parens, 1-28. Washington: Georgetown UP.

22. Prinz, Jesse J. 2004. Gut reactions: A perceptual theory of the emotions. Oxford: Oxford UP.

23. Birnbacher, Dieter. 2002. Der künstliche Mensch-ein Angriff auf die menschliche Würde? In Der künstliche Mensch. Körper und Intelligenz im Zeitalter ihrer technischen Reproduzierbarkeit, ed. K. Kegler and M. Kerner, 165-193. Köln: Bouvier.

24. Kosfeld et al. 2005. Oxytocin increases trust in humans. Nature 435(2): 673-676.

25. De Sousa, Ronald. Sex, drugs and Mahler. Reflections on Martha Nussbaum's Upheavals of Thought" [March 5, 2004, www.chass.utoronto.ca/ sousa/UPHEAVALS-APA. pdf, accessed in April 2009].

26. Stephan, Achim. 2003. Zur Natur künstlicher Gefühle. In Natur und Theorie der Emotion, ed. A. Stephan and H. Walter. Paderborn: Mentis.

27. Rescher, Nicholas. 1988. Rationality: A philosophical inquiry into the nature and the rationale of reason. Oxford: Oxford UP.
28. Nussbaum, Martha. 2004. Emotions as judgements of value and importance. In Thinking about feeling: Contemporary philosophers on emotion, ed. R.C. Solomon, 19-89. Oxford: Oxford UP.

29. De Sousa, Ronald. Emotion, The Stanford Encyclopedia of Philosophy (First published Mon Feb 3, 2003; substantive revision Thu Jan 14, 2010), Wyndham Thiessen (ed.) (2010), URL: http://plato.stanford.edu/entries/emotion/.

30. Goldie, Peter. 2000. The Emotions: A Philosophical Exploration. Oxford: Clarendon Press.

31. Freedman, Carol. 1998. Aspirin for the mind? Some ethical worries about psychopharmolacology. In Enhancing human Traits: Ethical and Social Implications., ed. E. Parens, 135150. Washington DC: Georgetown UP.

32. D'Arms, Justin, and Daniel Jacobson. 2003. The significance of recalcitrant emotions (Or Anti-QuasiJudgmentalism). Philosophy Supplement 52: 127-145.

33. Solomon, Robert C. 2003. The Rationality of Emotions. Reprinted in: Not Passion's Slave: Emotions and Choice, edited by R.C. Solomon, New York et al. 34-41.

34. Slater, Louise. 1999. Prozac diary. New York: Penguin.

35. Bostrom, Nick. 2003. Human genetic enhancement: A Transhumanist Perspective. The Journal of Value Inquiry 87: 493-506.

36. Healy, Dan. 1997. The Anti-Depressant Era. Cambridge, Mass: Harvard UP.

37. Klerman, George L. 1972. Psychotropic Hedonism vs. Pharmacological Calvinism. The Hastings Center Report 2 (4): 1-3.

38. Helm, Bennett. 2001. Emotional reason: Deliberation, motivation, and the nature of value. Cambridge: Cambridge UP.

39. Harré, Rom; Harrot, W. G. (eds.). 1996. The emotions: Social, cultural and biological dimensions. London/New Delhi: Sage Publications.

40. Parens, Erik. 2005. Authenticity and ambivalence: Toward understanding the enhancement debate. Hastings Center Report 35(3): 34-41.

41. Roettger-Rössler, Birgitt. 2004. Die kulturelle Modellierung des Gefühls: Ein Beitrag zur Theorie und Methodik ethnologischer Emotionsforschung anhand indonesischer Fallstudien. Münster: LIT.

42. Trilling, Leonard. 1971. Sincerity and authenticity. Cambridge Mass: Harvard UP.

43. Bostrom, Nick. 2008. Why I want to be a posthuman when I grow up. Medical Enhancement and Posthumanity, eds. Bert Gordijn and Ruth Chadwick, Dordrecht: Springer, 107-137. 